\title{
Study of the effect of amino-functionalized multiwall carbon nanotubes on dry sliding wear resistance properties of carbon fiber reinforced thermoset polymers
}

\author{
G. Pincheira ${ }^{1}$ - C. Montalba ${ }^{1}$ - W. Gacitua ${ }^{3}$ - H.-M. Montrieux ${ }^{4}$ • \\ J. Lecomte-Beckers ${ }^{4} \cdot$ M. F. Meléndrez ${ }^{1} \cdot$ P. Flores ${ }^{1,2}$
}

Received: 30 July 2015/Revised: 26 November 2015/ Accepted: 5 January 2016

(C) Springer-Verlag Berlin Heidelberg 2016

\begin{abstract}
This work investigates the effect of multiwall carbon nanotubes (MWCNTs) on the mechanical and tribological behavior of a fiber reinforced composite (FRC). Fiber reinforced composites and nano-engineered FRCs are manufactured by resin transfer molding. In-plane tensile tests, in-plane shear tests and through-thickness compression tests are used to assess the influence of MWCNTs on the material mechanical behavior. Pin on disk dry sliding tests are used to quantify the effect of MWCNTs on the friction coefficient and the specific wear rate. It was determined that (1) MWCNTs have an influence on the improvement on both the through-thickness compression strength and the specific wear rate, and (2) they do not influence the material stiffness, in-plane tensile and shear strengths and the friction coefficient. It is assumed that the observed improvements are due to the demonstrated positive influence of the MWCNTs effect on the matrix/reinforcement interfacial strength and on the matrix fracture toughness.
\end{abstract}

Keywords Multiwall carbon nanotubes - Fiber reinforced composites · Mechanical testing - Wear resistance

$\triangle$ P. Flores

pfloresv@udec.cl

1 Department of Materials Engineering (DIMAT), Faculty of Engineering, University of Concepcion, 270 Edmundo Larenas, Box 160-C, 4070409 Concepcion, Chile

2 Department of Mechanical Engineering (DIM), Faculty of Engineering, University of Concepcion, 219 Edmundo Larenas, Box 160-C, 4070409 Concepcion, Chile

3 Department of Wood Engineering, University of Bío-Bío, Collao 1202, Box 5-C, 4081112 Concepcion, Chile

4 Special Metallic Materials, B52, University of Liege, 1 Chemin des Chevreuils, Sart Tilman, 4000 Liege, Belgium 


\section{Introduction}

The study of the tribological behavior of fiber reinforced composites (FRCs) based on polymer matrix increases the possibilities for machine elements optimal design. The constituents (type and content) of the FRCs play a relevant role on the material mechanical behavior, wear rate and friction coefficient. Hence, a proper material design must be focused on the required application. FRCs have been demonstrated to be self-lubricant [1, 2] and corrosion resistant besides having the proper mechanical performance (specific stiffness and strength, fracture toughness, fatigue behavior) for structural applications. This multifunctional feature of FRCs is interesting for machine element design, as shown in [3-6], during the designing of bearings.

To improve the composite wear behavior, some research has been focused on the study of the influence of fillers in the matrix on the material wear resistance. Larsen et al. [7] reported that the addition of nano-CuO (1 vol.\%) and micro-scale PTFE (5 vol.\%) particles (separately) on the reinforcement of epoxy carbon/aramid fibers has a minor improvement in wear, but without producing differences in friction. These authors concluded that the friction and wear properties are controlled by the fibers. Su et al. [8] reported that the addition of nano- $\mathrm{CaCO}_{3}(5 \mathrm{wt} . \%)$, nano- $\mathrm{SiO}_{2}$ (5 wt. \%) and nano- $\mathrm{TiO}_{2}(5 \mathrm{wt} . \%)$ contributed to increase the wear resistance a carbon fabric/phenolic resin composite. This improvement is associated with the observed changes on the transfer film. Suresha et al. [9] reduced wear in epoxy carbon fiber reinforced by using a graphite filler (5 and $10 \mathrm{wt} \%$ ). The wear reduction using graphite filler is associated with reduction in the removal of fiber, a phenomenon that can be linked to the switch of the wear mechanism from microcracking to microplowing/microcutting. The above examples were developed under dry sliding conditions.

The improvement of the bonding at the matrix/reinforcement interface can reduce the removal of fiber. Indeed, as established by Lee et al. [10], if the fracture toughness of the matrix/reinforcement interface exceeds the minimum toughness of either constituent and the fracture in the reinforcement is not favorable, the resulting wear debris will be smaller in relation to the reinforcement size, thereby improving the wear resistance.

Several authors, using different manufacturing techniques, have demonstrated that the incorporation of multiwall carbon nanotubes (MWCNTs) on FRCs increases the strength of the matrix/reinforcement interface. For example, in [11-13] MWCNTs were grafted onto carbon fibers using the chemical vapor deposition method, whereas [14] and [15] described the modification of the surface of sized fibers by aqueous suspension deposition of MWCNTs. In addition, [15] and [16] described the dispersion of MWCNTs into the resin (epoxy) to prepare a suspension. For each of the reported techniques, significant improvements on the epoxy/fiber/ MWCNTs interfacial shear strength (IFSS) were obtained (from $11 \%$ [12] to $175 \%$ [11]), with the amount of improvement depending on the chosen technique, the orientation and length of the MWCNTs, as well as the content (as established by the model proposed by Yang et al. [17]) and the surface treatment of the MWCNTs, 
among other features. According to [18], the increase of the IFSS due to the addition of MWCNTs can explain the increase of the interlaminar shear strength (ILSS). The addition of MWCNTs to the resin or to the FRCs also increases the material fracture toughness of the material, as demonstrated in [19] or [20] for epoxy resin and in [21-24] for FRCs (glass fiber and carbon fiber reinforcement).

Besides, experimental evidence has established that the addition of MWCNTs in epoxy resin enhances its wear resistance. Friederich and Schlarb [25] indicated the relevance of the mixing method and the carbon nanotube treatment and its content on the wear resistance of epoxy resin with MWCNTs, with $1.0 \mathrm{wt} . \%$ being the optimal loading of MWCNTs to achieve the minimum specific wear rate. Cui et al. [26] demonstrated that the addition of MWCNTs to epoxy is an efficient method to improve the wear resistance and to lower the friction coefficient; they demonstrated that a 0.5 -wt.\% amino-functionalized MWCNT composite achieves a reduction of $41.3 \%$ on the wear rate compared to neat epoxy.

In this work, the influence of the addition of commercially amino-functionalized MWCNTs on the in-plane and out-of-plane mechanical performance of epoxy was assessed, as well as the friction coefficient and the wear resistance under dry sliding conditions of the modified epoxy in epoxy twill weave carbon FRC manufactured using resin transfer molding (RTM). The composite was designed with ca. $50 \%$ fiber volume fraction and the nFRC includes $0.3 \mathrm{wt} . \%$ of MWCNTs in the resin. These values were set in agreement with the mechanical requirements (heavy-duty machine elements conception) and the feasibility of achieving good MWCNTs infiltration (see for example [27] and [28]) according to the selected manufacturing procedure. The manufactured configurations were tested according to the ASTM D 3039 and ASTM D 4255 for the in-plane mechanical properties and according to ASTM G 99 for the friction coefficient. Also, specific wear rate and throughthickness compression test were performed according to [29]. The effects of the MWCNTs on the composite were determined from the tests results.

\section{Experimental description}

\section{Selected materials}

The matrix is composed of the L20 epoxy resin with an EPH 161 hardener, which is produced by Momentive, USA and purchased from R\&G composites, Germany. According to the technical data from the manufacturer, this resin system is designed for heat resistant components up to $120{ }^{\circ} \mathrm{C}$ and groutings to approximately $10 \mathrm{~mm}$ thick. In addition, curing occurs virtually free of shrinkage. The resin viscosity in solution with the hardener at $25{ }^{\circ} \mathrm{C}$ is $700 \mathrm{cP}$ and at $35{ }^{\circ} \mathrm{C}$ is $295 \mathrm{cP}$ (the measurements were made using a Fungilab Alpha series rotational viscometer). The reinforcement is a twill $2 / 2$ woven fabric of $204 \mathrm{~g} / \mathrm{m}^{2}$ constructed by 200 tex Carbon $3 \mathrm{~K}$ yarns (the same in the warp and weft directions). The carbon fibers are Tenax ${ }^{\circledR}$-E HTA40 3K, and their manufacturer specifications are as follows: tensile modulus of $238 \mathrm{GPa}$, tensile strength of $3950 \mathrm{MPa}$, density of $1.76 \mathrm{~g} / \mathrm{cm}^{3}$ and ca. $1.3 \%$ sizing based on epoxy resin. The fabrics are manufactured by Engineered 
Cramer Composites, Germany. Nanocyl (Belgium) provided the NC $3152 \mathrm{NH}_{2}$ surface-modified MWCNTs. The MWCNTs are produced via the catalytic carbon vapor deposition process.

\section{Manufacturing process}

The materials studied were manufactured using RTM. In this procedure, the resin is injected into the mold at 4 bar and the composite is cured at room temperature for $24 \mathrm{~h}$ and post-cured for $15 \mathrm{~h}$ at $100{ }^{\circ} \mathrm{C}$. The differences between the FRC and the nano-engineered FRC (nFRC) were due to the resin preparation and the injection temperature. For the FRC, the mixing ratio is 100:25 parts by weight of resin to hardener mixed using mechanical stirring at room temperature. In the preparation of the nFRC, 0.3-wt.\% MWCNTs are poured into the resin and mixed in a propeller stirrer (Velp, model Stirrer Type BS) for $10 \mathrm{~min}$ at $520 \mathrm{rpm}$. The mixture is then placed in an ultrasonic bath (Elma, model Elmasonic P) at $30{ }^{\circ} \mathrm{C}$ for $90 \mathrm{~min}$ at $80 \mathrm{kHz}$. Because the addition of MWCNTs contributes to increase the resin viscosity up to $840 \mathrm{cP}$, the mixture is then heated to $35^{\circ} \mathrm{C}$ to obtain a viscosity below $380 \mathrm{cP}$, followed by adding the hardener (at a 100:25 weight ratio) and stirring the solution. The infusion is performed at $35{ }^{\circ} \mathrm{C}$, and the mold is pre-heated at the same temperature. A visual inspection of the doped epoxy on the inlet and outlet hoses of the system is used to verify that MWCNTs filtration or precipitation did not occur.

Two composites geometries were manufactured by means of the procedure above described. The first one is a 12 plies laminate of $544 \mathrm{~mm} \times 250 \mathrm{~mm} \times 2.8 \mathrm{~mm}$ used to characterize the in-plane mechanical behavior. The second one is a 45 plies laminate of $250 \mathrm{~mm} \times 150 \mathrm{~mm} \times 10 \mathrm{~mm}$ used to obtained the specimens for the through-thickness compression and tribological tests.

\section{Laminates features}

The laminate thickness is measured in at least ten points per manufactured laminate using a Vernier caliper. The density is measured by immersion method according to ASTM D 792 standard (five samples per material). The fiber volume fraction is computed according to the ASTM D 3171 (method II). The hardness is measured with a Barcol (Impressor GYZJ-934-1) as indicated the ASTM D 2583 and the micro-Vickers hardness (using $500 \mathrm{~g}$ load during $10 \mathrm{~s}$ ) is additionally measured for the 45 plies laminates. All of this information is presented in Table 1, where the same physical properties of the materials is achieved (Fiber volume fraction and Density are similar).

\section{Mechanical tests}

The mechanical performance of the materials is determined from in-plane tensile tests, in-plane shear tests and through-thickness compression tests. All the tests were performed under quasi-static conditions in an Instron 8801 testing machine provided with a $100 \mathrm{kN}$ load cell. The specimens were cut by diamond wheel cutter. The 
Table 1 Laminates features

\begin{tabular}{|c|c|c|c|c|c|}
\hline $\begin{array}{l}\text { Number } \\
\text { of plies }\end{array}$ & Material & Parameter & $\begin{array}{l}\text { Average } \\
\text { value }\end{array}$ & $\begin{array}{l}\text { Standard } \\
\text { deviation (SD) }\end{array}$ & $\begin{array}{l}\text { Relative } \\
\text { SD \% }\end{array}$ \\
\hline \multirow[t]{8}{*}{12} & \multirow[t]{4}{*}{ FRC } & Thickness (mm) & 2.81 & 0.08 & 2.8 \\
\hline & & Density $\left(\mathrm{g} / \mathrm{cm}^{3}\right)$ & 1.46 & 0.01 & 0.7 \\
\hline & & Fiber volume fraction & 0.49 & 0.02 & 4.1 \\
\hline & & Barcol hardness & 65.1 & 4.7 & 7.2 \\
\hline & \multirow[t]{4}{*}{$\mathrm{nFRC}$} & Thickness (mm) & 2.77 & 0.09 & 3.2 \\
\hline & & Density $\left(\mathrm{g} / \mathrm{cm}^{3}\right)$ & 1.45 & 0.01 & 0.7 \\
\hline & & Fiber volume fraction & 0.51 & 0.02 & 3.9 \\
\hline & & Barcol hardness & 66.7 & 4.4 & 6.6 \\
\hline \multirow[t]{10}{*}{45} & \multirow[t]{5}{*}{ FRC } & Thickness (mm) & 10.18 & 0.04 & 0.4 \\
\hline & & Density $\left(\mathrm{g} / \mathrm{cm}^{3}\right)$ & 1.43 & 0.01 & 0.7 \\
\hline & & Fiber volume fraction & 0.52 & 0.01 & 1.9 \\
\hline & & Barcol hardness & 61.7 & 3.6 & 5.8 \\
\hline & & Micro-Vickers hardness & 38 & 14 & 37 \\
\hline & \multirow[t]{5}{*}{$\mathrm{nFRC}$} & Thickness (mm) & 10.19 & 0.07 & 0.7 \\
\hline & & Density $\left(\mathrm{g} / \mathrm{cm}^{3}\right)$ & 1.44 & 0.01 & 0.7 \\
\hline & & Fiber volume fraction & 0.52 & 0.01 & 1.9 \\
\hline & & Barcol hardness & 61.2 & 6.0 & 9.8 \\
\hline & & Micro-Vickers hardness & 36 & 15 & 42 \\
\hline
\end{tabular}

Quality control for both types of plates studied

mechanical parameters are presented in Table 2, where each value was obtained from the average of five tests. In this table, the average value (AV) is complemented with the standard deviation (SD), the relative standard variation (R. SD) and the $95 \%$ interval of confidence (IC).

\section{Tensile tests}

The tensile tests were performed according to the ASTM D 3039 with a crosshead speed of $1 \mathrm{~mm} / \mathrm{min}$. The specimens were obtained from the 12 plies laminates. The specimens were clamped using hydraulic wedge grips. The stress was computed from the load cell data and the initial specimen cross section. The longitudinal strain was measured using a strain gage (length: $9.5 \mathrm{~mm}$, width: $3.5 \mathrm{~mm}$, gage length: $5 \mathrm{~mm}$, gage factor 2.1, gage resistance: $120 \Omega$ ). The elastic modulus was computed using a linear regression on the linear (elastic) range of the stress-strain curve and the tensile strength was set at the maximal stress level.

\section{In-plane shear tests}

The in-plane shear tests were performed according to the ASTM D 4255 at a crosshead speed of $0.3 \mathrm{~mm} / \mathrm{min}$. A two-rail testing device was embedded into the testing machine. The specimens were obtained from the 12 plies laminates. The 
Table 2 Mechanical properties of material composites prepared

\begin{tabular}{lllllrl}
\hline Test & Parameter & Material & AV & SD & R. SD \% & $\begin{array}{l}\text { Limits of } \\
\text { IC }(95 \%)\end{array}$ \\
\hline Tensile & Elastic modulus (GPa) (TM) & FRC & 54.1 & 1.4 & 2.6 & \pm 2.6 \\
& & nFRC & 55.9 & 1.7 & 3.0 & \pm 3.1 \\
& Tensile strength (MPa) (TS) & FRC & 692 & 81 & 11.7 & \pm 149 \\
& & nFRC & 692 & 47 & 6.8 & \pm 86 \\
& Poisson ratio, $v$ (PC) & FRC & 0.058 & 0.008 & 13.8 & \pm 0.015 \\
& & nFRC & 0.058 & 0.014 & 24.1 & \pm 0.026 \\
& Ultimate strain (US) & FRC & 0.012 & 0.001 & 8.3 & \pm 0.002 \\
In-plane shear & & nFRC & 0.011 & 0.001 & 9.1 & \pm 0.002 \\
& Shear modulus (GPa) (SM) & FRC & 3.3 & 0.6 & 18.2 & \pm 1.1 \\
& & nFRC & 3.5 & 1.1 & 31.4 & \pm 2.0 \\
& Shear strength (MPa) (SS) & FRC & 49 & 3.4 & 6.9 & \pm 6.2 \\
& & nFRC & 49 & 5.3 & 10.8 & \pm 9.7 \\
Through-thickness & Elastic modulus (GPa) & FRC & 8.7 & 0.8 & 9.2 & \pm 1.5 \\
compression & (TTCM) & nFRC & 9.3 & 1.2 & 12.9 & \pm 2.2 \\
& Compressive strength MPa & FRC & 637 & 20 & 3.1 & \pm 37 \\
& (TTCS) & nFRC & 690 & 26 & 3.7 & \pm 48 \\
\hline
\end{tabular}

stress was computed from the load cell data and the initial specimen cross section. The shear strain was measured using a strain gage (length: $9.5 \mathrm{~mm}$, width: $3.5 \mathrm{~mm}$, gage length: $5 \mathrm{~mm}$, gage factor 2.1 , gage resistance: $120 \Omega$ ) that was placed as indicated in the norm. The in-plane shear modulus was obtained using a linear approach for a shear strain range of 0-0.002 (due to the non-linear elasticplastic behavior of the material under the imposed condition) and the shear strength was set at the achievement of a shear strain of 0.05 , according to the norm.

\section{Out-of-plane compression tests}

The out-of-plane compression tests were performed according to [29] at a crosshead speed of $0.5 \mathrm{~mm} / \mathrm{min}$. The specimens were $10 \mathrm{~mm} \times 10 \mathrm{~mm} \times 10 \mathrm{~mm}$ cubes obtained from the 45 plies laminates. The specimens were compressed between two lubricated steel plates. The stress was computed from the load cell data and the initial specimen cross section. The longitudinal strain was measured using a strain gage (length: $6 \mathrm{~mm}$, width: $2.5 \mathrm{~mm}$, gage length: $2 \mathrm{~mm}$, gage factor 2.0, gage resistance: $120 \Omega$ ). The through-thickness compressive elastic modulus was computed using a linear regression on the linear (elastic) range of the stress-strain curve and the through-thickness compression strength was set at the maximal stress level.

\section{Tribological testing}

The tribological tests were performed on a pin on disk apparatus (High Temperature Tribometer from CSM Instruments) under dry sliding conditions (Fig. 1). The 


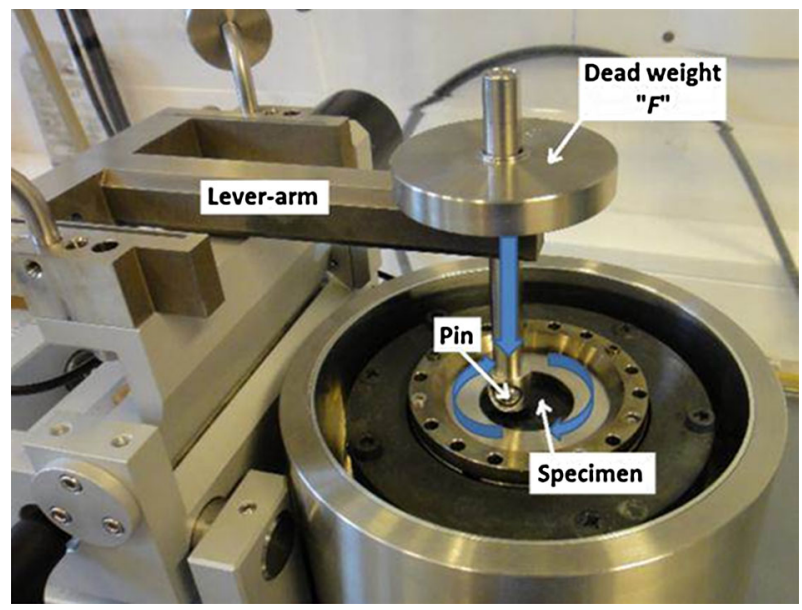

Fig. 1 Pin on disk apparatus. Tribological properties are studied in it

Fig. 2 Wear specimen. Wear path over the specimen is observed after test

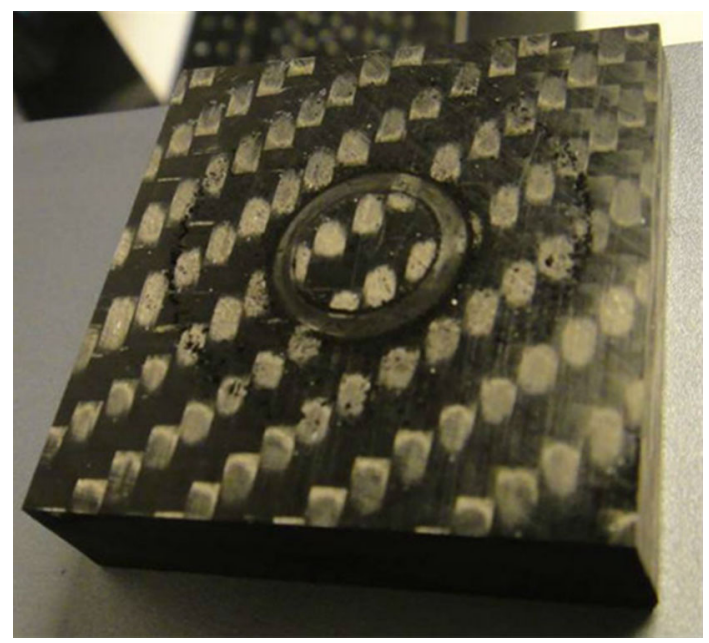

specimen is a $38 \mathrm{~mm} \times 38 \mathrm{~mm} \times 10 \mathrm{~mm} 45$ plies composite, which is fixed on the machine. The specimen is perpendicularly loaded by a stainless steel ball that slides (without rotation) over the material surface following a circular path (as shown in Fig. 2). The imposed load $(F)$ is set to $2 \mathrm{~N}$, the ball diameter is $10 \mathrm{~mm}$ and its speed $(v)$ is set to $0.98 \mathrm{~m} / \mathrm{s}$. The testing equipment records the frictional force during the test to compute the friction coefficient. The initial pressure $(p)$ imposed by the ball over the specimen is approximately 107.5 MPa for the nFRC and 102.7 MPa for the FRC, as computed by the Hertz contact theory using the data from Table 2, leading to the $p v$ testing condition of 105.4 and $100.6 \mathrm{MPa} \mathrm{m} / \mathrm{s}$ for the $\mathrm{nFRC}$ and the FRC, respectively. 
The tests were performed at three sliding distances $(L): 10,000,30,000$ and $50,000 \mathrm{~m}$. Each test was repeated three times (new specimens were used in every test). The mass of each of the specimens was measured before and after performing the tests using a balance (precision of $0.01 \mathrm{mg}$ ). The mass loss $(\Delta m)$ was used in the Eq. 1 to determine the specific wear rate ( $\rho$ denotes the density of the specimen established on Table 1).

$$
W r=\frac{\Delta m}{\rho F L}\left(\mathrm{~mm}^{3} / \mathrm{N} \mathrm{m}\right) .
$$

\section{Results and discussion}

\section{Mechanical Properties}

The obtained mechanical properties for FRC and nFRC composites from quasistatic tensile, shear and compression tests are summarized in Table 2. The normalized material parameters with respect to the values from the FRC composite are shown in (Fig. 3) in order to facilitate the comparison of the mechanical features under consideration.

It is assumed, as established in the introduction, that the inclusion of the MWCNTs improves the strength of the matrix/reinforcement interface and the matrix fracture toughness. Under quasi-static conditions, for tensile tests the effect of the improved strength is negligible. Likewise, a similar result is presented in [30]. The same result was found for the in-plane shear test, at least under the studied strain range, where the matrix behavior had a major role (see, for example, the explanation presented in [31]). The increase of the nFRC through-thickness compressive strength is attributed to the influence of the performance of the improved matrix/reinforcement interface on the failure mechanisms (see $[32,33]$ for a deeper study on the influence of the interface).

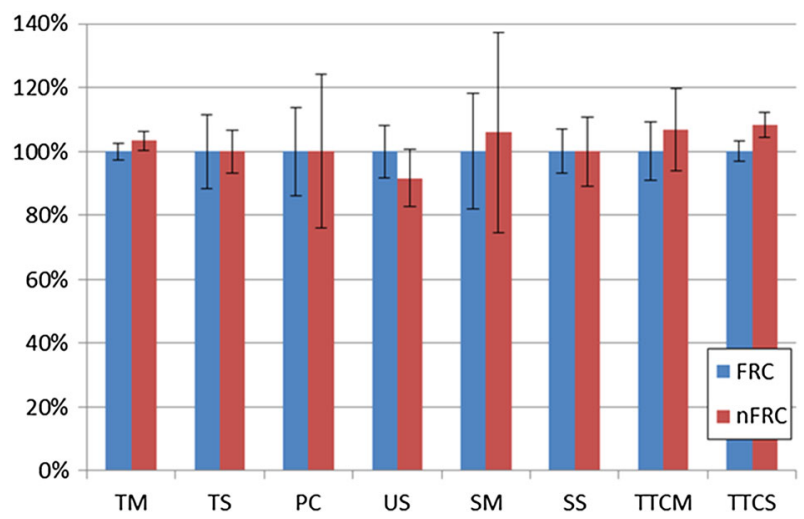

Fig. 3 Normalized material parameters. A comparison of mechanical properties is shown and it is possible to see improvements in some properties due to carbon nanotubes addition 


\section{Tribological tests}

Figure 4 illustrates the steady-state friction coefficient during the test. It can be observed that the friction coefficient is similar for every case. On the other hand, Figs. 5 and 6 indicate the measured mass loss and specific wear rate (computed using Eq. 1) for both material configurations at the different sliding distances. The average values are used to develop the ideas established in the following paragraphs (note that the results obtained from the nFRC are more stable). Figure 5 shows that at $10,000 \mathrm{~m}$ of sliding distance, there is not a remarkable difference on the mass loss between the FRC and the nFRC. However, at 30,000 and 50,000 $\mathrm{m}$ sliding distances, the amount of mass loss is lower for the nFRC.

Fig. 4 Friction coefficient. Variation of coefficient during the tests in both materials are observed, similar values are observed in almost all cases
Fig. 5 Mass loss. Mass loss of the specimen for different sliding distances shown the same behavior but lower values for $\mathrm{nFRC}$
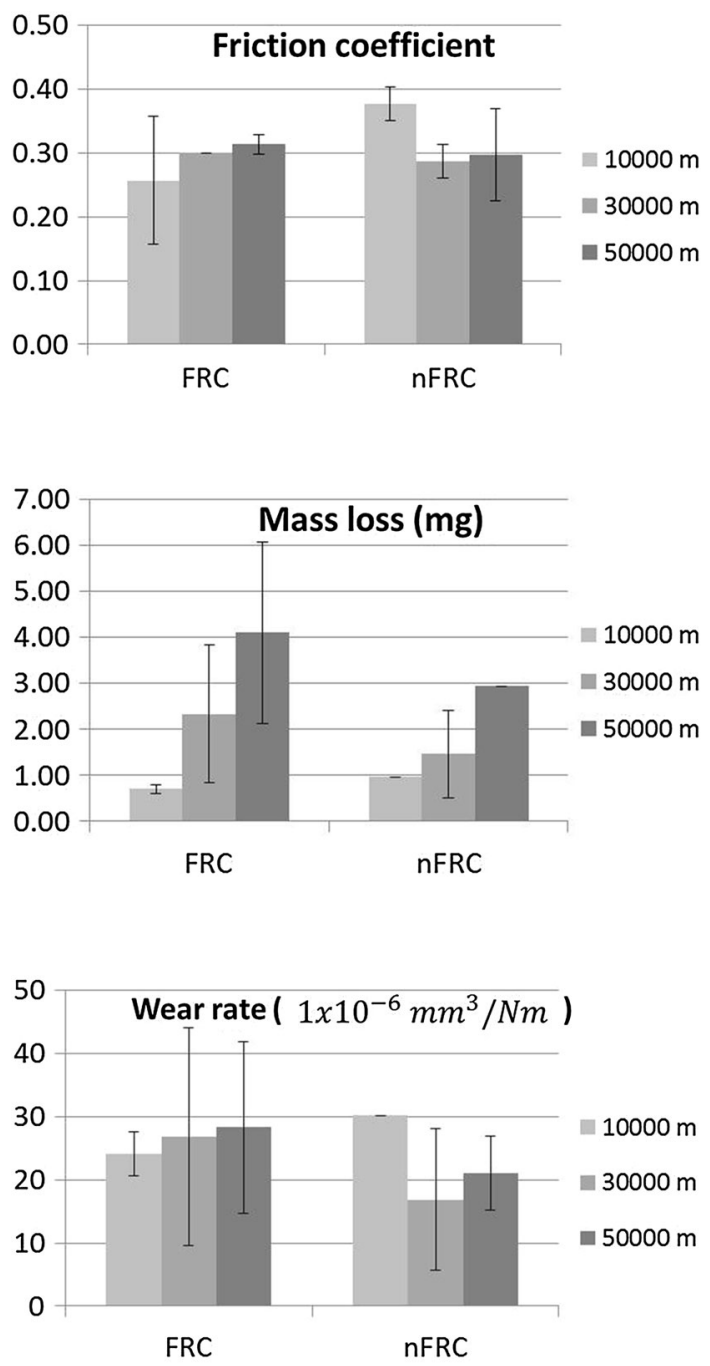

Fig. 6 Wear rate. Specific wear rate are observed for different sliding distances and it is possible to see a reduction for higher distances in $\mathrm{nFRC}$ 
Figure 6 shows that the specific wear rate for the FRC is similar at the tested sliding distances. Note that the specific wear rates for the nFRC experiences a reduction of the specific wear rate at the higher sliding distances. The results obtained from the tribological tests indicate that FRC and nFRC do not change the value of the steady-state friction coefficient considerably. This result, together with the fact that the behavior of both material configurations at a sliding distance of $10,000 \mathrm{~m}$ is similar in mass loss and specific wear rate (due to the high influence of the surface resin layer), is used to deduce that the role of the transfer film at this stage is not altered by the amount of MWCNTs contained in the nFRC debris. In this case, the improvement on the wear resistance reported in [26] for epoxy resin with a similar amount of amino-functionalized MWCNTs, but for different loading conditions, were not reproduced. Nevertheless, reducing specific wear rate for nFRC at higher sliding distances is associated with the CNTs influence on matrix/fiber interface, helping to reduce interfacial debonding and keep the broken fiber in the composite surface due to mechanical interlocking of CNTs with matrix, chemical bonding between CNTs and bulk materials and local stiffening of polymer matrix near fiber/matrix.

\section{Microscopic analysis}

The worn surfaces of the specimen at the different sliding distances were observed using a scanning electron microscope (SEM, JSM-6380 JEOL). The worn surfaces of the specimens were cleaned and then coated with a thin gold layer. Figures 7 and 8 show selected micrographs of the surfaces of FRC and nFRC, respectively. The selection was based on the representativeness of the wear mechanisms. In both figures, the images (a) and (b) represent the specimens state at a sliding distance of $10,000 \mathrm{~m}$, (c) and (d) at 30,000 $\mathrm{m}$ and (e) and (f) at 50,000 m. In the figures, the blue arrow represents the sliding direction. Figure 7 a shows the effects when the pin passes over a poorly impregnated area, where it is possible to identify: (1) the boundary between the original surface and the first ply of visible fiber; (2) a transversally broken fiber; (3) the debris trapped between fibers; (4) an obliquely broken fiber; (5) the beginning of fiber-matrix debonding. Figure $7 \mathrm{~b}$ shows the behavior of the material in a well-impregnated zone, where it is possible to observe micro-plowing marks in the sliding direction and: (1) fractured fiber; (2) fiber pullout and the subsequent disorientation of the removed material; (3) the beginning of fiber-matrix debonding.

In Fig. 7c, d, micro-cracking was the most commonly observed phenomenon. Figure 7c shows: (1) and (4) a micro-crack that divides the matrix; (2) and (3) broken fibers; (4) several micro-cracks in the original surface. Figure 7d shows: (1) fiber pullout; (2) broken fibers disoriented in the sliding direction; (3) and (4) microcracking and the resin debonding zone. Figure 7e shows: (1) and (2) several broken fibers; (3) the boundary between the worn surface and the resin surface parallel to the sliding direction. Figure $7 \mathrm{f}$ presents: (1) and (2) plowing marks on the matrix due to plastic deformation in the resin, which, according to [7], occurs through the application of cyclic loads on the specimens and the generation of high temperatures 

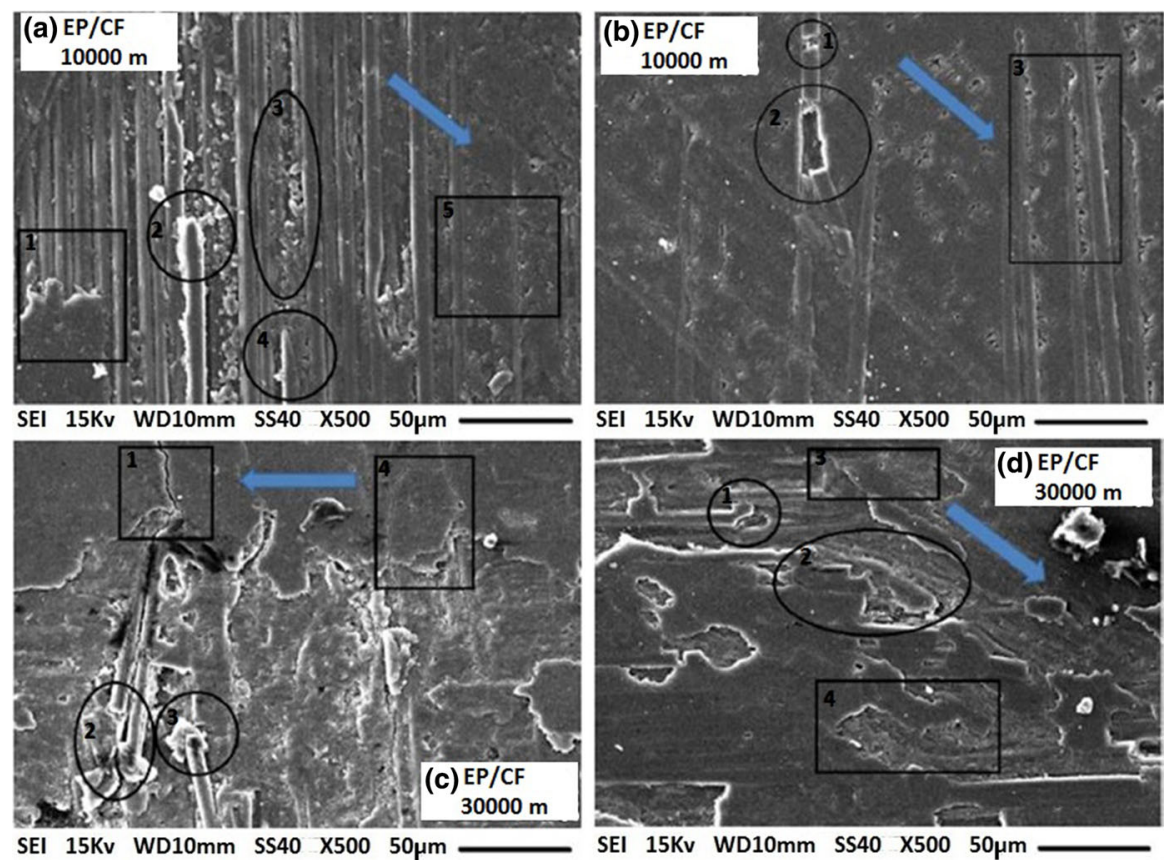

SEI $15 \mathrm{Kv}$ WD10mm SS40 X500 $50 \mu \mathrm{m}$

SEI 15Kv WD10mm SS40 X500 50 10
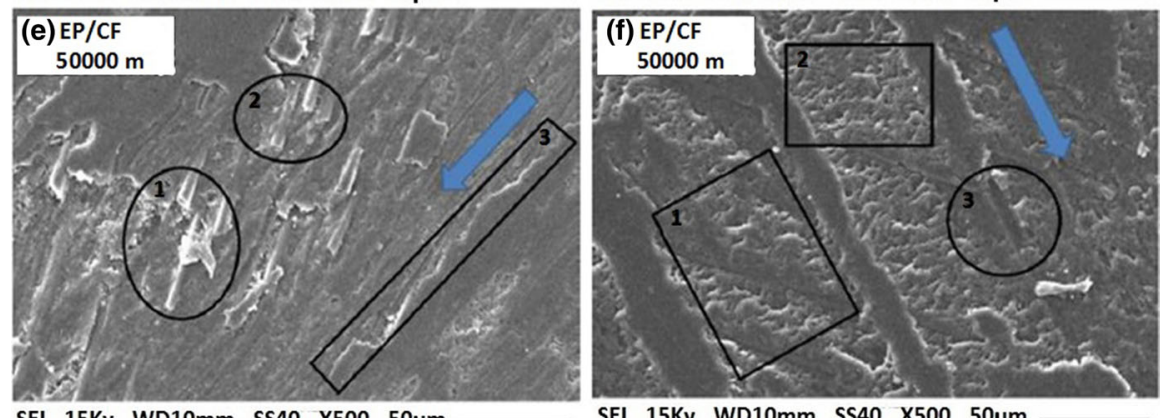

SEI $15 \mathrm{Kv}$ WD10mm SS40 X500 $50 \mu \mathrm{m}$

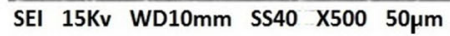

Fig. 7 SEM images of FRC. a, b Represent sliding distance of $10,000 \mathrm{~m}$ where the first wear mechanisms are observed. c, d Corresponding to $30,000 \mathrm{~m}$, micro-cracking and broken fiber are present. e, f Are images for $50,000 \mathrm{~m}$, several wear mechanisms are observed

(approaching $T_{g}$ ) in some points associated to the real contact area; (3) shows debonding of the fiber-matrix zone.

Figure 8 shows a selection of the most common wear mechanisms observed during the SEM inspection of the nFRC; note that these mechanisms are the same as those in the former case. Nevertheless, the frequency of these wear mechanisms, especially matrix cracks, were much lower for nFRC than for FRC. According to the evidence, the improvement experienced by the nFRC on the wear resistance at higher sliding distance is attributed to the influence of the MWCNTs content on the 

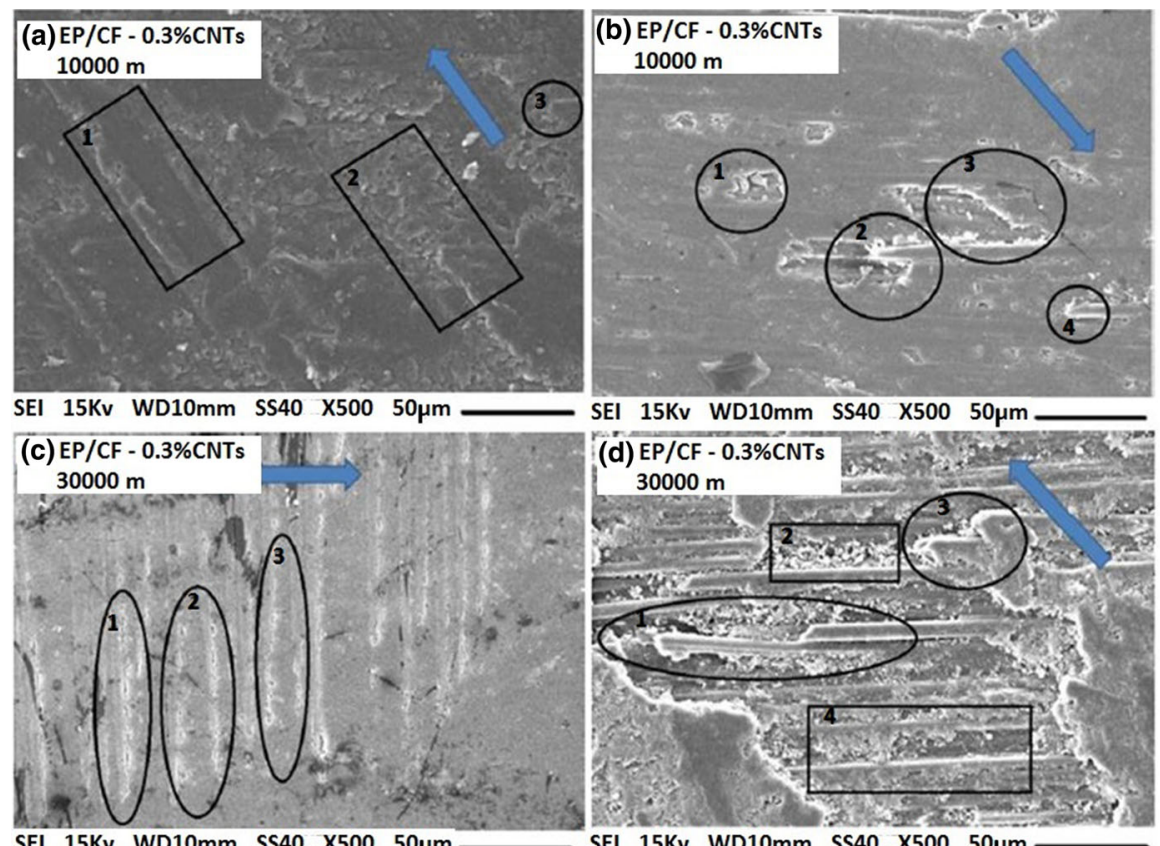

SEI $15 \mathrm{Kv}$ WD10mm SS40 X500 50 $\mathrm{mm}$
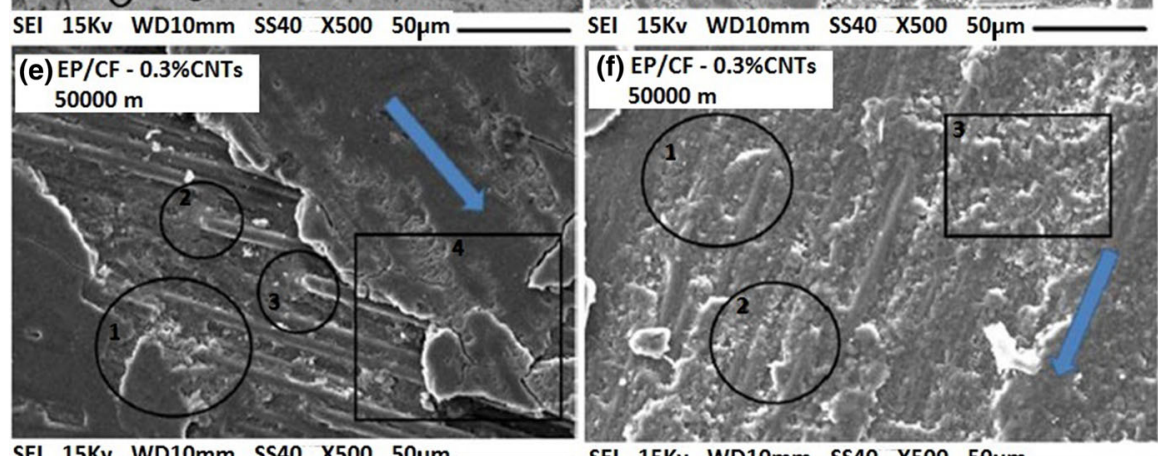

SEI $15 \mathrm{Kv}$ WD10mm SS40 X500 50 $\mathrm{mm}$

SEI $15 \mathrm{Kv}$ WD10mm SS40 X500 50 $\mathrm{mm}$

Fig. 8 SEM images of nFRC. SEM images of nFRC. a, b Represent sliding distance of 10,000 m. c, d Corresponding to $30,000 \mathrm{~m}$. e, f Are images for 50,000 m. The same wear mechanisms are present but in a much lower frequency

increase of the IFSS and on the matrix fracture toughness and hence, according to [10] to the improvement to the wear reduction.

The main idea was taken into account for the development of this work was to use carbon nanotubes (MWCNTs) functionalized with amine groups. These groups $\left(-\mathrm{NH}_{2}\right)$ covalently anchored to the MWCNTs could operate in the same way as operating the hardener used in this type of curing reaction (Previous antecedents showed a shift of the amine signal belonging to the nanotubes after the curing process). Therefore, when reacting the epoxy groups with the amino groups of the hardener and nanotubes, it is likely to be formed a three-dimensional network where the nanotubes are incorporated, as shown in Fig. 9. The resin components used were 


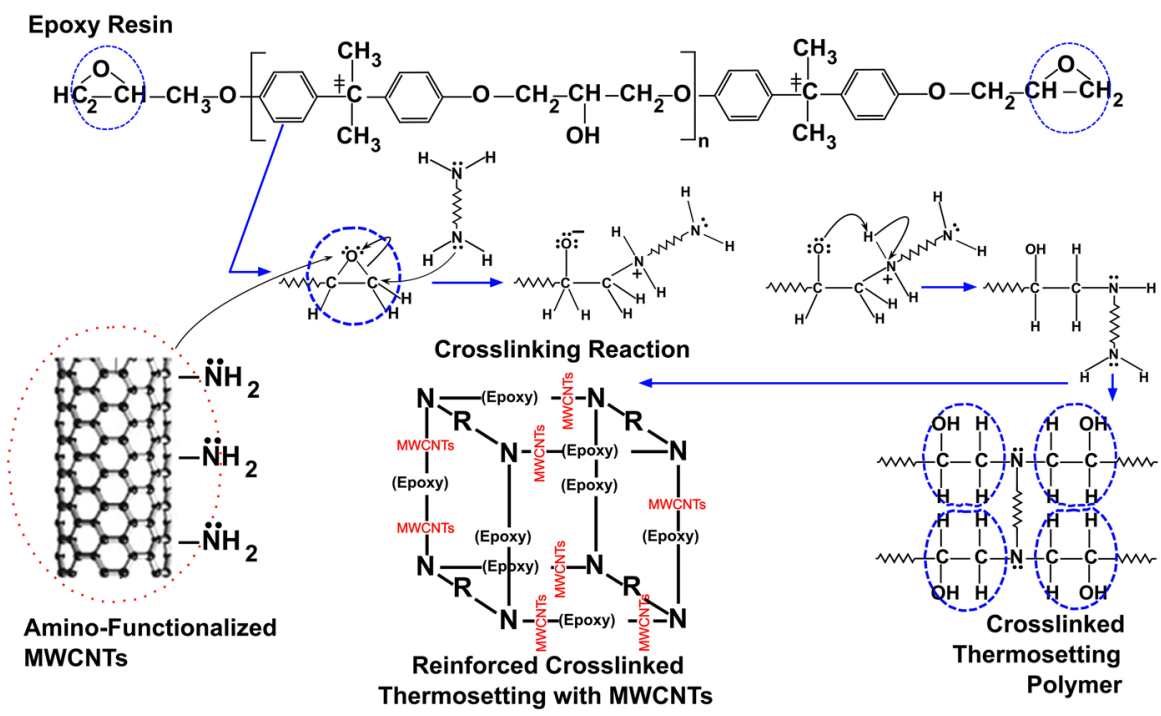

Fig. 9 Mechanism of the curing reaction using $\left(\mathrm{NH}_{2}\right)$-MWCNT and different types of crosslinkers. A three-dimensional covalent network coupled with the nanotubes is obtained

bisPhenol-A-Epichlorhydrin (70 \%), Bisphenol-F-Epichlorhydrin (20\%) and an epoxidized molecule that gives flexibility to the thermoset polymer as 1.6-Bis(2.3Epoxypropoxy)hexane $(10 \%)$. On the other hand, the hardener is composed of diethylenetriamine (50\%), Bisphenol A (49\%) present as a solvent and m-phenylenebis(methylamine) (1\%). Basically, all the curing reaction focuses on bisphenol A and F (Epichlorhydrin) and diethylenetriamine, coupled with the amine groups of the MWCNTs.

Depending on the chemical structure of curing agent used and conditions of cure, it is possible to obtain thermosetting polymers with mechanical properties ranging from extreme flexibility to full hardness and rigidity, high adhesive strength, good tensile properties and high temperature insulation. Therefore, a possible increase in the degree of crosslinking because the $\left(\mathrm{NH}_{2}\right)$-MWCNTs, would mean an improvement in the mechanical properties of the composites. However, this was not found in the above results (this may be because the fiber can decrease the degree of crosslinking of the resin). In Table 2, a significant improvement in the compounds are not evidenced; this can be seen by comparing the obtained material with and without $\left(\mathrm{NH}_{2}\right)$-MWCNTs. But, although the friction coefficient does not change, the specific wear rate if tends to reduce. The above occurs because functionalizing nanotubes create defects in both walls at its ends, in many cases the tubes are broken into smaller pieces resulting in a drastic loss in mechanical and electrical properties. The improvement in the rate of wear is due to the nanotubes improve the matrix/reinforcement interface. But due to its functionalization it is not sufficient to reduce the coefficient of friction of the material because their mechanical properties decreased. 


\section{Conclusions}

From the dry-sliding tribology tests (pin on disk) the inclusion of MWCNTs on the composite were found to (a) not modify the friction coefficient and (b) tend to reduce the specific wear rate. It can be remarked from the SEM images that the nFRC exhibited a reduced amount of wear compared to the FRC, primarily in the matrix cracking. This improvement of the wear resistance is attributed to the effect of the MWCNTs on the enhancement of the strength of the matrix/reinforcement interface and on the matrix fracture toughness and not to an improvement of the resin transfers film effect.

The inclusion of the MWCNTs in the epoxy carbon FRCs manufactured by RTM improves the through-thickness compressive stiffness and strength. Moreover, the other mechanical properties under study are not affected by incorporating MWCNTs.

Acknowledgments The financial support by CONICYT through the projects Fondef (D08i1138 and IT13i10054) and CONICYT Regional (CIPA/R08C1002). The authors would like to thank the National Commission for Scientific and Technological Research, CONICYT (Ministry of Education Government of Chile) by PhD scholarship Grant No. 21100601 of G. Pincheira. The content is solely the responsibility of the authors and does not necessarily represent the official views of the CONICYT.

\section{References}

1. Wu J, Cheng XH (2009) The tribological properties of Kevlar pulp reinforced epoxy composites under dry sliding and water lubricated condition. Wear 26:1293-1297

2. Suresha B, Kunigal Shiva Kumar, Seetharamu S, Sampath Kumaran P (2010) Friction and dry sliding wear behavior of carbon and glass fabric reinforced vinyl ester composites. Tribol Int 43:602-609

3. Kim BC, Lee DG (2009) Development of a spherical bearing with uni-directional carbon/epoxy composite. Compos Struct 89:102-109

4. Park DC, Lee SM, Kim BC, Kim HS, Lee DG (2006) Development of heavy-duty hybrid carbonphenolic hemispherical bearings. Compos Struct 73:88-98

5. Yu HN, Kim SS, Lee DG (2009) Optimum design of aramid-phenolic/glass-phenolic composite journal bearings. Compos Part A 40:1186-1191

6. Kim SS, You HN, Hwang IU, Lee DG (2009) Development of the carbon/phenolic composite shoulder bearing. Compos Struct 88:26-32

7. Larsen TO, Andersen TL, Thorning B, Vigild ME (2006) The effect of particle addition and fibrous reinforcement on epoxy-matrix composites for severe sliding conditions. Wear 264:857-868

8. Su F, Zhang Z, Liu W (2006) Mechanical and tribological properties of carbon fabric composites filled with several nano-particles. Wear 260:861-868

9. Suresha B, Kishore S, Seetharamu S, Kumaran PS (2009) Investigations on the influence of graphite filler on dry sliding wear and abrasive wear behaviour of carbon fabric reinforced epoxy composites. Wear 267:1405-1414

10. Lee GY, Dharan CKH, Ritchie RO (2002) A physically-based abrasive wear model for composite materials. Wear 252:322-331

11. Lv P, Feng Y, Zhang P, Chen H, Zhao N, Feng (2011) W. Increasing the interfacial strength in carbon fiber/epoxy composites by controlling the orientation and length of carbon nanotubes grown on the fibers. Carbon 49:4665-4673

12. Sager RJ, Klein PJ, Lagoudas DC, Zhang Q, Liu J, Dai L, Baur JW (2009) Effect of carbon nanotubes on the interfacial shear strength of T650 carbon fiber in an epoxy matrix. Compos Sci Technol 69:898-904

13. An F, Lu C, Li Y, Guo J, Lu X, Lu H, He S, Yang Y (2012) Preparation and characterization of carbon nanotube-hybridized carbon fiber to reinforce epoxy composite. Mater Des 33:197-202 
14. Li M, Gu Y, Liu Y, Li Y, Zhang Z (2013) Interfacial improvement of carbon fiber/epoxy composites using a simple process for depositing commercially functionalized carbon nanotubes on the fibers. Carbon 52:109-221

15. Godara A, Gorbatikh L, Kalinka G, Warrier A, Rochez O, Mezzo L, Luizi F, van Vuure AW, Lomov SV, Verpoest I (2010) Interfacial shear strength of a glass fiber/epoxy bonding in composites modified with carbon nanotubes. Compos Sci Technol 70:1346-1352

16. Chandrasekaran VCS, Advani SG, Santare MH (2010) Role of processing on interlaminar shear strength enhancement of epoxy/glass fiber/multi-walled carbon nanotube hybrid composites. Carbon 48:3692-3699

17. Yang L, He X, Mei L, Tong L, Wang R, Li Y (2012) Interfacial shear behavior of 3D composites reinforced with CNT-grafted carbon fibers. Compos Part A 43:1410-1418

18. Chandrasekaran VCS, Advani SG, Santare MH (2011) Influence of resin properties on interlaminar shear strength of glass/epoxy/MWNT hybrid composites. Compos Part A 42:1007-1016

19. Gojny F, Wichmann MHG, Fiedler B, Schulte K (2005) Influence of different carbon nanotubes on the mechanical properties of epoxy matrix composites-a comparative study. Compos Sci Technol 65:2300-2313

20. Tang Y, Ye L, Zhang Z, Friederich K (2013) Interlaminar fracture toughness and CAI strength of fibre-reinforced composites with nanoparticles-a review. Compos Sci Technol 86:26-37

21. Godara A, Mezzo L, Luizi F, Warrier A, Lomov SV, Van Vuure AW, Gorbatikh L, Moldenaers P, Verpoest I (2009) Influence of carbon nanotube reinforcement on the processing and the mechanical behavior of carbon fiber/epoxy composites. Carbon 47:2914-2923

22. Karapappas P, Vavouliotis A, Tsotra P, Kostopoulos V, Paipetis A (2009) Enhanced fracture properties of carbon reinforced composites by the addition of multi-wall carbon nanotubes. J Compos Mater 43:977-985

23. Lee SH, Kim H, Hang S, Cheong SK (2012) Interlaminar fracture toughness of composites laminates with CNT-enhanced nonwoven carbon tissue interleave. Compos Sci Technol 73:1-8

24. Mujika F, Vargas G, Ibarretxe J, De Gracia J, Arrese A (2012) Influence of the modification with MWCNT on the interlaminar fracture properties of long carbon fiber composites. Compos Part B 43:1336-1340

25. Jacobs O, Schäbel B (2008) Wear behavior of carbon nanotube-reinforced polyethylene and epoxy composites. In: Friederich K, Schlarb AK (eds) Tribology of polymeric nanocomposites. In: Briscoe BJ (ed) Tribology and Interface Engineering Series, vol 55. Elsevier, UK, pp 209-242

26. Cui LJ, Geng HZ, Wang WY, Chen LT, Gao J (2013) Functionalization of multi-wall carbon nanotubes to reduce the coefficient of friction and improve the wear resistance of multi-wall carbon nanotube/epoxy composites. Carbon 54:277-282

27. Jiménez-Suárez A, Campo M, Sánchez M, Romón C, Ureña A (2012) Influence of the functionalization of carbon nanotubes on calendaring dispersion effectiveness in a low viscosity resin for VARIM processes. Compos Part B 43:3482-3490

28. Aguilar-Ventura I, Lubineau G (2013) The effect of bulk-resin CNT-enrichment on damage and plasticity in shear-loaded laminated composites. Compos Sci Technol 84:23-30

29. Kim BC, Park DC, Kim BJ, Lee DG (2010) Through-thickness compressive strength of a carbon/ epoxy composite laminate. Compos Struct 92:480-497

30. De Greef N, Gorbatikh L, Godara A, Mezzo L, Lomov S, Verpoest I (2011) The effect of carbon nanotubes on the damage development in carbon fiber/epoxy composites. Carbon 49:4650-4664

31. Fernández C, Medina C, Pincheira G, Canales C, Flores P (2013) The effect of multiwall carbon nanotubes on the in-plane shear behavior of epoxy fiber reinforced composites. Compos Part B 55:421-425

32. Gonzalez C, Llorca J (2007) Mechanical behavior of unidirectional fiber-reinforced polymers under transverse compression: microscopic mechanisms and modeling. Compos Sci Technol 67:2795-2806

33. Medina C, Molina-Aldareguía J, González C, Melendrez M, Flores P, Llorca J (2015) Comparison of push-in and push-out tests for measuring interfacial shear strength in nano-reinforced composite materials. J Compos Mater. doi:10.1177/0021998315595115 